\title{
Pengaruh Pendekatan Permainan dan Tingkat Intelligence Quotient (IQ) terhadap Keterampilan Bermain Bola Basket
}

\author{
The Effect of Game Approach and Intelligence Quotient (IQ) \\ Towards Basketball Skills
}

\author{
Masayu Rizka Risjanna, Amung Ma'mun \& Tite Juliantine \\ Universitas Pendidikan Indonesia, Bandung, Jawa Barat, Indonesia \\ masayurizka@upi.edu, amung@upi.edu,\& titejuliantine@upi.edu
}

Naskah diterima tanggal 02/06/2019, direvisi akhir tanggal 24/06/2019, disetujui tanggal 31/07/2019

\begin{abstract}
Abstrak
Tujuan penelitian ini adalah untuk mengetahui pengaruh pendekatan permainan dan tingkat intelligence quotient (IQ) terhadap keterampilan bermain bola basket yang diterapkan pada atlet UKM bola basket putri UPI Bandung. Penelitan ini menerapkan dua pendekatan permainan yaitu Tactical Games Approach dan Game Sense Approach. Penelitian ini menggunakan pendekatan kuantitatif dengan metode Experimental, dan desain penelitian faktorial $2 \times 2$ yang dilakukan pada 30 orang atlet yang dibagi dalam 4 kelompok yaitu 2 kelompok di IQ tinggi dan 2 kelompok di IQ rendah. Instrumen yang digunakan untuk mengukur tingkat IQ adalah Advanced Progressive Matrices (APM) dan Games Performance Assessment Intrument (GPAI) untuk mengukur keterampilan bermain bola basket. Hasil pengolahan dan analisis data penelitian yang diperoleh menunjukkan bahwa 1) Terdapat perbedaan pengaruh antara pendekatan permainan dan tingkat IQ terhadap keterampilan bermain bola basket. 2) Terdapat interaksi antara pendekatan permainan dan tingkat IQ terhadap keterampilan bermain bola basket. 3) Terdapat perbedaan pengaruh pendekatan permainan pada kelompok tingkat IQ tinggi terhadap keterampilan bermain bola basket. 4) Terdapat perbedaan pengaruh pendekatan permainan pada kelompok tingkat IQ rendah terhadap keterampilan bermain bola basket. Dan berdasarkan hasil olah data tersebut diketahui bahwa pendekatan Tactical Games Approach lebih baik diterapkan pada kelompok yang memiliki tingkat IQ tinggi dan pendekatan Game Sense Approach lebih baik diterapkan pada kelompok yang memiliki tingkat IQ rendah.
\end{abstract}

Kata kunci: Tactical Games Approach, Game Sense Approach, Tingkat Intelligence Quotient (IQ), Keterampilan Bermain Bola basket

\begin{abstract}
The purpose of this study was to determine the effect of the game approach and the intelligence quotient (IQ) level on the basketball skills applied to the UPI Bandung women's basketball athletes in Bandung. This research applies two game approaches, which is Tactical Games Approach and Game Sense Approach. This study uses a quantitative approach with the Experimental method with a $2 \times 2$ factorial design carried out on 30 athletes divided into 4 groups namely 2 groups in high IQ and 2 groups in low IQ. The instruments used to measure intelligence quotient (IQ) levels are Advanced Progressive Matrices (APM) and Games Performance Assessment Instruments (GPAI) to measure skills for playing basketball. The results of the processing and analysis of research data obtained showed that 1) There were differences in influence between the game approach and IQ level on the skill of playing basketball. 2) There is an interaction between the game approach and IQ level on basketball skills. 3) There is a difference in the influence of the game approach on the group of high IQ level on the skill of playing basketball. 4) There is a difference in the influence of the game approach on the low IQ level on the skill of playing basketball. And based on these results it is known that the Tactical Games Approach approach is better applied to groups that have a high IQ level and the Game Sense Approach approach is better applied to groups that have a low IQ level.
\end{abstract}

Keywords: Tactical Games Approach, Game Sense Approach, Intelligence Quotient (IQ) Level, Basketball Skill. 


\section{PENDAHULUAN}

Beberapa penelitian baru-baru ini menganalisis mengenai pentingnya pelatihan dalam olahraga tim atau beregu untuk pencapaian hasil yang menguntungkan dalam olahraga misalnya, bola basket (Gómezharo \& Salmerón-gómez, 2015) Salah satu olahraga tim adalah olahraga permainan bola basket (Piette, Pham, \& Anand, 2011). Olahraga permainan bola basket merupakan salah satu olahraga permainan yang popular di dunia, penggemarnya yang berasal dari segala usia merasakan bahwa olahraga bola basket merupakan olahraga yang menyenangkan, kompetitif, mendidik, menghibur dan menyehatkan sehingga dapat dimainkan oleh semua usia. Selain itu bola basket merupakan olahraga permainan yang cukup mendapat perhatian tinggi di kalangan olahraga pendidikan, rekreasi maupun prestasi. Bola basket dimainkan oleh 2 tim yang terdiri dari 5 orang pemain yang tujuan dari masing-masing tim adalah untuk mencetak angka ke dalam keranjang lawan dan mencegah lawan untuk mencetak angka ke keranjang sendiri (FIBA 2017:6).

Dalam olahraga permainan bola basket, menguasai keterampilan bermain secara individu merupakan kemampuan yang harus dimiliki setiap pemain bola basket. Salah satu ciri khas permainan bola basket yang kompetitif adalah mengharuskan setiap regu yang saling lawan untuk memasukkan bola ke keranjang lawan dan berusaha menjaga keranjang sendiri agar lawan tidak dapat mencetak angka. Hal tersebut mengharuskan setiap pemain bola basket menguasai keterampilan-keterampilan individu seperti shooting, passing, dribbling, dan rebound, serta kerja tim untuk menyerang atau bertahan adalah persyaratan agar berhasil dalam memainkan olahraga ini (Bazanov \& Haljand, 2017). Dalam bola basket skill dan teknik mengacu kepada memberi bola (passing), menerima bola, menggiring bola (dribble), menembak (shooting), menyerang dan bertahan (Kwong, 1986). Teknisnya setiap pemain bola basket akan menampilkan kemampuan yang dimilikinya untuk membawa tim memenangkan pertandingan.
Tim dapat memenangkan pertandingan bergantung pada kemampuan individu yang harus menguasai beberapa teknik dalam permainan bola basket seperti passing, shooting, dribbling, maupun rebound serta kerjasama regu (Csataljay, Donoghue, Hughes, \& Dancs, 2017).

Hal tersebut digunakan oleh guru atau pelatih untuk mengajarkan keterampilan dalam bentuk teknik atau pendekatan tradisional. Namun pendekatan teknik saja dianggap kurang menggugah pemain untuk terlibat penuh, juga tidak meningkatkan pemahaman dan kemampuan bermain dalam cabang olahraga yang diajarkan salah satunya dalam olahraga permainan bola basket yang menyebabkan kurangnya pemahaman konsep dan tujuan bermain dalam permainan bola basket baik dalam menyerang maupun bertahan. Masalah yang dirasakan dengan metode pengajaran dan pelatihan tradisional, termasuk kebosanan dari latihan keterampilan yangberulang; faktabahwaketerampilanyang dipraktikkan dengan baik sering rusak ketika dimasukkan ke dalam situasi permainan dan dalam pendekatan pembelajaran tradisional permainan biasanya didahului kegiatan diskrit (yang membutuhkan lebih banyak waktu dan tidak menekankan pergantian antar olahraga), meskipun banyak permainan memiliki kesamaan taktis (Breed \& Spittle, 2011:4).

Selain keterampilan teknik, sebagai seorang atlet bola basket dibutuhkan keterampilan taktis sebagai pengetahuan tentang penggunaan teknik dalam situasi tertentu dalam bermain bola basket. Artinya saat situasi permainan sedang berlangsung bagaimana caranya agar kemampuan teknik seorang pemain dapat digunakan melalui taktik permainan agar tujuan tercapai (Mcmorris \& Mcmorris, 2006).

Pendekatan taktis ini didasari oleh temuan Bunker dan Thrope di tahun 1982, melalui konsep teaching games for understanding (TGfU). Menurut Mitchell, Oslin, \& Griffin (2013:8) mengatakan bahwa pendekatan taktis bertujuan untuk meningkatkan performa permainan dari siswa atau pemain dengan mengkombinasikan 
kesadaran taktis dan pelaksanaan keterampilannya. Selain itu Bunker \& Thrope dalam Breed \& Spittle (2011:8) mengatakan bahwa penekanan pada pertimbangan taktis dalam permainan akan mendorong siswa untuk menikmati permainan dan mengembangkan kesadaran permainan taktis, serta memahami pentingnya keterampilan teknis tertentu dan ketika mereka diperlukan dalam permainan.

Seseorang yang terampil dan memiliki banyak pengetahuan tentang bola basket menunjukkan kinerja yang lebih baik dalam situasi permainan yang sebenarnya. Seseorang harus terlebih dahulu mengembangkan basis pengetahuan dalam olahraga yang diberikan sebelum dapat mencukupi dan mengembangkan keterampilan pengambilan keputusan yang baik. Cakupannya mengenai pengetahuan tentang aturan permainan, posisi pemain, mencetak angka (goal) dan sub-tujuan permainan, dan seterusnya (French \& Thomas, 1987). Istilah lain yang menggambarkan perkembangan pendekatan ini yaitu tactical games yang dikembangkan oleh Griffin, Mitchel \& Oslin dan game sense yang dikembangkan oleh Australian Sports Commission (Kirk \& Macphail, 2002). Seperti yang dikatakan oleh Setiawan (2010) bahwa dikemudian hari, beberapa ahli pendidikan jasmani melakukan pengembangan TGfU seperti pada the tactical games model dan game sense.

Penting bagi pemain untuk mengetahui apa yang harus dilakukannya serta bagaimana melakukannya dalam situasi permainan. Secara jelas kedua pendekatan ini (tactical games approach and game sense approach) mengasumsikan prioritas pertama dalam proses belajarnya ialah sisi kognitif, psikomotor kemudian afektif. Kemudian menurut Metzler (2005:408) menjelaskan bahwa siswa pada awalnya menyelesaikan masalah taktis yang diberikan melalui domain kognitif, dimana kemudian difasilitasi situasi permainan untuk penampilan keterampilan dalam domain psikomotor.

Pencapaian performa tim yang baik tidak terlepas dari aspek psikologis setiap individu yang harus dikembangkan. Sejalan dengan yang dikatakan oleh Firmasnyah (2015:8) bahwa kenyataan di lapangan bahwa aspek psikologis berperan dominan pada atlet dalam olahraga kompetitif. Di antara faktor psikologis yang mempengaruhi prestasi adalah tingkat kecerdasan atau $I Q$ (Latifah, Rusdiana, Ugelta, Budiana \& Karmini, 2017). Kemampuan potensi individu berkaitan dengan kecerdasan yang dimiliki oleh seseorang. Khodijah (2016:89) mengatakan bahwa seseorang yang memiliki kecerdasan tinggi akan mampu belajar cepat, serta berulang kali dapat memilih tindakan yang efektif dalam situasi yang rumit. Intelligence quotient (IQ) adalah indeks tingkat relatif kecerdasan seseorang, dibandingkan dengan yang lain. Intelligence quotient (IQ) adalah salah satu elemen psikologis yang berarti ukuran kemampuan intelektual, analitis (kemampuan menganalisis), dan rasio dan logika seseorang (Wahab dalam Kusuma \& Kristiyanto, 2017).

Kecerdasan merupakan salah satu faktor yang sering menentukan kemenangan dalam pertandingan salah satunya dalam cabang olahraga seperti bola basket. Aspek psikologis yang merupakan level intelligence quotient (IQ) merupakan elemen yang memiliki peran penting untuk keterampilan basket, terutama dalam menguasai dan menganalisis berbagai keterampilan gerakan dalam bola basket, yang artinya Ada hubungan positif dan signifikan antara intelligence quotient (IQ) dengan keterampilan bola basket, artinya semakin tinggi tingkat intelligence quotient (IQ), semakin tinggi pula keterampilan bola basketnya (Kusuma \& Kristiyanto, 2017).

\section{Tactical Games Approach terhadap Keterampilan Bermain}

Tactical games approach (TGA) berasal dari model permainan mengajar untuk memahami model oleh karena itu kerangka kerja TGA menekankan pembelajaran dan pelatihan keterampilan (skill) dalam konteks permainan, yang bertentangan dengan pendekatan teknik di mana keterampilan dipraktikkan secara terpisah (Gubacscollins, Olsen, \& Gubacs-collins, 2013). Tujuan dari tactical games approch adalah 
untuk mengembangkan pemahaman kinerja dalam permainan. Hal ini sejalan dengan apa yang dikatakan Mitchell, Oslin, \& Griffin (2013:8) bahwa tujuan dari pendekatan taktis adalah untuk meningkatkan kinerja permainan siswa, yang melibatkan dengan menggabungkan kesadaran taktis dan pelaksanaan keterampilan. Penerapan tactical games approach dalam prosesnya memanfaatkan "masalah-masalah taktis" sebagai perantara untuk mencapai tujuan. Metzler (2005). mengatakan bahwa pendekatan ini menekankan penggunaan versi permainan yang dibutuhkan dan sesuai dengan perkembangan di semua tingkatan. Klasifikasi permainan untuk membantu dan memahami struktur yang mendasari setiap game dengan mengidentifikasi atributatribut umum di antara permainan yang diklasifikasikan serupa. Sistem klasifikasi memiliki empat kategori utama: target, fielding/run scoring, net/wall, dan invasion (Dyson, Griffin, \& Hastie, 2004). Selain itu, asumsi yang paling mendasar bahwa performa kemampuan motorik akan lebih cakap jika mengikuti pembelajaran kognitif/ aspek pengetahuan. Penting bagi setiap siswa atau pemain untuk mengetahui apa yang harus dilakukan dan bagaimana melakukannya dalam setting atau situasi permainan. Tactical games approach dapat memprioritaskan aspek pengambilan keputusan dari game dan mendorong siswa atau pemain untuk menggunakan keterampilan pemecahan masalah mereka (Dyson, Griffin, \& Hastie 2004).

Hasil penelitian Hawkins et al., (2015) mengatakan bahwa melalui pendekatan permainan taktis (tactical games approach) dapat membantu dan mendorong kebutuhan penggunaan dalam keterampilan berfikir kritis dalam membuat keputusan untuk melakukan skill yang diperlukan dalam suatu olahraga.

\section{Game Sense Approach Terhadap Keterampilan Bermain}

Game sense approach dikembangkan di Australia selama 1990-an melalui kolaborasi antara Rod Thorpe, Komisi Olahraga Australia (ASC) dan pelatih
Australia. GSA adalah pendekatan yang berpusat pada permainan, dikembangkan sebagai lawan dari apa yang telah disebut sebagai pembinaan olahraga "tradisional", yang memiliki praktik pelatihan pusat organisasi dan gaya pengajaran langsung dari pedagogi (Light, 2013). Beberapa hasil yang berpotensi yang dikaitkan dengan game sense approach untuk pengajaran dan pelatihan. Game Sense merupakan pembahasan khusus olahraga dari game pengajaran untuk memahami model yang bertujuan mengatasi masalah yang dirasakan dengan metode pengajaran dan pembinaan tradisional (teknis). Dalam Game Sense Approach siswa atau pemain dihadapkan dengan tantangan yang dipecahkan dalam permainan yang terstruktur, daripada harus berlatih keterampilan teknis secara terpisah (Launder \& Piltz, 2006).

Game sense approach memberikan kontribusi yang signifikan terhadap pengembangan area bermain tertentu seperti pemahaman taktis, membaca permainan, membuat keputusan, kemandirian pemain dan perasaan umum para pemain. Pendekatan game sense memiliki penekanan pada "coach as educator", pelatih sebagai pendidik yang terlibat dalam pertanyaan pemain untuk menghubungkan pemain dengan makna dan tujuan kegiatan serta mendorong mereka untuk berpartisipasi dalam diskusi tentang aspek dari taktis permainan (Georgakis \& Light, 2007). Game sense dirancang untuk menantang pelatihan keterampilan dan permainan olahraga dekontekstual pengetahuan tradisional dan untuk menyediakan kerangka kerja desain alternatif untuk pengajaran olahraga (Pill, 2013). Dalam pembentukan game sense sebagai tujuan pengajaran dan pembinaan olahraga, game sense kembali mengartikulasikan keterampilan sebagai kinerja teknik dalam menanggapi tuntutan situasi permainan, daripada reproduksi bergaya "textbook techniques". Dengan kata lain, keterampilan adalah bukti dari "thinking players" yang dapat membaca permainan, merespons dengan gerakan tanpa bola (off-the-ball) yang sesuai, menjalankan 
respons gerakan yang sesuai (berhasil dalam konteks permainan) ketika penguasaan bola (on-the ball) dan kemudian dapat kembali untuk membaca permainan lagi (Issue, 2003).

Hasil penelitian lain dari Thembelihle \& Timothy (2018) menyebutkan guru atau pelatih yang menggunakan pendekatan game sense harus menghargai dan memahami bahwa pengembangan olahraga memiliki kompleksitas kognitif di dalamnya sebagai pendekatan yang dapat dikembangkan untuk menghasilkan kemampuan berpikir yang lebih baik dari peserta didik dan pemain. Pendekatan ini juga dikembangkan untuk alasan praktis dan tidak hanya dari sudut pandang teoretis. Pemain dalam kategori olahraga yang berbeda perlu menggunakan penilaian persepsi agar mereka dapat mengantisipasi dan membaca permainan dengan baik di bawah konteks waktu dan ruang kinerja yang terkompresi untuk membuat respons motorik yang relevan dan kompleks selama pertandingan. Pendekatan game sense dalam penelitian ini memberdayakan guru dan pelatih dengan pemahaman taktis yang lebih besar tentang permainan dan dapat mempromosikan perubahan dalam pengembangan olahraga yang mengarah ke pengembangan pergeseran pola pikir ke pelatihan yang berpusat pada permainan di Zimbabwe.

Pendidikan dan pelatihan akan terlaksana dengan baik dan benar jika didukung dengan pendekatan pada saat latihan yang memadai untuk meningkatkan kapasitas kemampuan potensi setiap individunya dengan baik. Kemampuan potensi individu berkaitan dengan kecerdasan yang dimiliki seseorang.

\section{Peran Intelligence Quotient (IQ)}

Kecerdasan dalam olahraga prestasi sangat dibutuhkan dan dapat menunjang atlet untuk terampil dalam aktivitas gerak, karena atlet dapat berpikir secara cepat dalam membuat keputusan yang harus dilakukan dengan tepat sehingga hasil penampilan bermain (performance) optimal yang diharapkan tercapai dengan baik, hal tersebut diperlukan dalam bermain bola basket. Latifah, Rusdiana, Ugelta, Budiana \& Karmini (2017) mengatakan bahwa kecerdasan adalah faktor penting yang sering menentukan kemenangan dalam olahraga. Terutama di cabang-cabang tertentu seperti sepak bola, bulu tangkis, tenis meja, bola basket, tenis, seni bela diri atau lainnya. Aspek psikologis yang merupakan level intelligence quotient (IQ) merupakan elemen yang memiliki peran penting untuk keterampilan basket, terutama dalam menguasai dan menganalisis berbagai keterampilan gerakan dalam bola basket (Kusuma \& Kristiyanto, 2017).

Berbagai faktor seperti pendekatan permainan dan tingkat potensi kecerdasan dalam proses latihan harus dipertimbangkan agar kinerja kognisi (cognitif performance) dan keterampilan bermain seorang pemain bola basket dapat dimaksimalkan. Pemain dengan keterampilan teknis yang terbatas dapat memainkan permainan jika mereka memiliki pemahaman taktis yang wajar, oleh karena itu kurangnya pengetahuan taktis dan kecerdasan adalah alasan yang signifikan untuk pelaksanaan keterampilan teknis yang buruk.

\section{Peran Pendekatan Permainan dan Tingkat Intelligence Quotient (IQ) Terhadap Keterampilan Bermain Bola basket}

Untuk menjadi pemain yang baik perlu menguasai dasar-dasar (dasar-dasar, teknik dan strategi) dari permainan bola basket. Masalah yang dirasakan dengan metode pengajaran dan pelatihan tradisional, termasuk kebosanan dari latihan keterampilan yangberulang; faktabahwaketerampilanyang dipraktikkan dengan baik sering rusak ketika dimasukkan ke dalam situasi permainan dan dalam pendekatan pembelajaran tradisional permainan biasanya didahului kegiatan diskrit (yang membutuhkan lebih banyak waktu dan tidak menekankan pergantian antar olahraga), meskipun banyak permainan memiliki kesamaan taktis (Breed \& Spittle, 2011:4).

Pendekatan tradisional mendorong guru dan pelatih untuk fokus pada pengajaran cara melakukan keterampilan (how to 
do a skill) sebelum mereka mangajarkan mengapa harus melakukan keterampilan itu (why) (Breed \& Spittle, 2011:8). Selain keterampilan teknik, sebagai seorang atlet bola basket dibutuhkan keterampilan taktis sebagai pengetahuan tentang penggunaan teknik dalam situasi tertentu dalam bermain bola basket. Artinya saat situasi permainan sedang berlangsung bagaimana caranya agar kemampuan teknik seorang pemain dapat digunakan melalui taktik permainan agar tujuan tercapai (Mcmorris \& Mcmorris, 2006). Maka dari itu pemilihan pendekatan dalam proses pelatihan olahraga khususnya olahraga permainan bola basket yang tepat dirasa sangat penting.

Selain itu, kondisi intelegensi atau kecerdasan ini dalam kaitannya dengan olahraga agar tetap bertambah dengan baik harus tetap memperoleh stimulus atau rangsangan untuk berfungsi, dengan cara atlet tersebut harus dibiasakan untuk menggunakan kemampuan inteleknya (Setiadi, 2001). Intelegensi yang tinggi juga berpengaruh besar terhadap pencapaian prestasi. Hal ini sejalan dengan penelitian yang dilakukan Edward dan Coleman dalam Setiadi (2001) menunjukkan bahwa orang dengan intelegensi tinggi akan memiliki prestasi yang lebih baik dibandingkan dengan orang yang memiliki intelegensi sedang atau rendah. Lalu hasil penelitian dari Kusuma \& Kristiyanto (2017) menjelaskan bahwa untuk dapat memiliki dan mengendalikan keterampilan dalam bola basket membutuhkan tingkat kecerdasan yang baik pula. Selain itu, seseorang juga dapat mengidentifikasi dan menganalisis kekurangan dan kelemahan gerakan keterampilan bola basket yang dipraktikkan sehingga dapat digunakan untuk memperbaiki atau meningkatkan keterampilan yang dimiliki. Hal tersebut menunjukkan dan membuktikan aspek psikologisnya yang merupakan level intelligence quotient (IQ) merupakan elemen yang memiliki peran penting untuk keterampilan basket, terutama dalam menguasai dan menganalisis berbagai keterampilan gerakan dalam bola basket.
Secara keseluruhan pendekatan tacticalgamesapproach lebihungguldaripada pendekatan game sense approach terhadap keterampilan bermain bola basket, karena model ini berfokus pada eksplorasi pemain dari berbagai kemungkinan permainan dan pada pembangunan respon yang memadai dalam permainan sisi kecil juga menekankan untuk mempertimbangkan kegunaan pengetahuan dan kompetensi yang perlu dikembangkan dalam pembelajaran bermain game. Dengan pertimbangan tersebut, pemain akan merujuk pada perumusan tugasnya, perilaku yang dapat diamati, dan isyarat sebelum benar-benar terlibat dalam tugas (Haneishi, 2014). Pendekatan tactical games didasarkan pada urutan permainan yang sesuai dengan perkembangan seperti aktivitas pembelajaran disebut bentuk permainan (game form) yang berfokus pada masalah taktis untuk dipecahkan pertama secara kognitif dan kemudian melalui pelaksanaan kinerja motor yang terampil (Metzler, 2005). Bentuk permainan (game form) harus mewakili permainan yang sebenarnya dan menggunakan situasi yang lebih untuk fokus pada pengembangan keterampilan taktis. Untuk menjadi representatif berarti bahwa bentuk permainan mengandung situasi realistis yang akan dihadapi ketika dalam permainan yang sebenarnya (Mitchell, Oslin, \& Griffin, 2013). Selain itu penerapan pendekatan tactical games dalam prosesnya memanfaatkan "masalah-masalah taktis" sebagai perantara untuk mencapai tujuan. Taktik dan keterampilan berkembang dalam urutan bentuk-bentuk permainan yang masing-masing berisi masalah taktis dinyatakan untuk menentukan tujuan pembelajaran tugas saat ini (Mitchell, Oslin, \& Griffin, 2013).Sedangkan pemberian masalah sekaligus pemecahannya dalam prosesnya bermaksud agar mampu mencari solusi atas kesulitan-kesulitan yang muncul (Mawarti, 2005).

\section{METODE PENELITIAN}

Metode yang digunakan dalam penelitian ini adalah pendekatan kuantitatif dengan metode Experimental. Populasi 
dalam penelitian ini merupakan atlet bola basket putri UPI Bandung dengan sampel sebanyak 30 atlet. Desain dalam penelitian ini seperti pada gambar 1 menggunakan desain faktorial $2 \times 2$.

Tabel 1. Desain penelitian faktorial $2 \times 2$

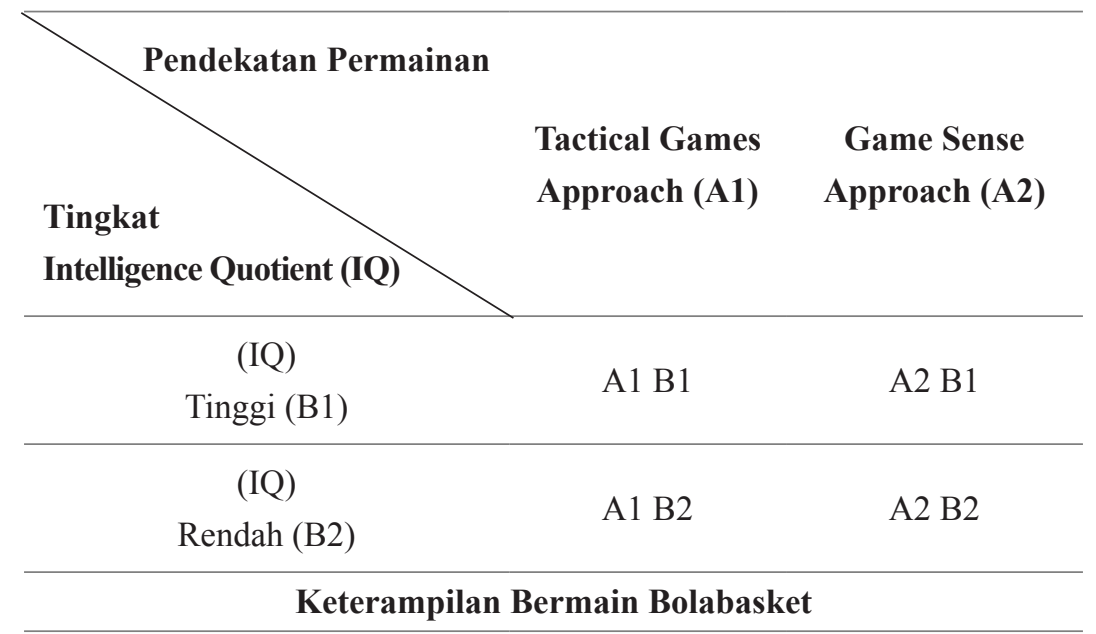

Berikutnya, instrument yang digunakan pertama advanced progressive matrices (APM) untuk mengetahui potensi intelegensi (tinggi rendah) dengan mengukur kemampuan Tingkat $I Q$. Menurut Khodijah (2016:92) menjelaskan bahwa intelegensi adalah kemampuan umum sesungguhnya yang dimiliki seseorang, akan tetapi $I Q$ adalah suatu indeks tingkat relatif intelegensi seseorang setelah dibandingkan dengan orang lain. Selanjutnya, tes keterampilan bermain bola basket dengan menggunakan game performance assesment instrument (GPAI) yang ditemukan oleh Mitchell, Oslin, \& Griffin (2013) Ada tujuh komponen sebagai penilaian GPAI menurut Metzler (2005) yaitu: 1) Kembali ke pangkalan (home base) maksudnya adalah seorang pemain yang kembali ke posisi semula setelah dia melakukan suatu gerakan keterampilan tertentu. 2) Menyesuaikan diri (adjust) maksudnya adalah pergerakan seorang pemain saat menyerang atau bertahan yang disesuaikan dengan tuntutan situasi permainan. 3) Membuat keputusan (decision making) dilakukan setiap pemain, setiap saat di dalam situasi apapun. 4) Melaksanakan keterampilan tertentu (skill execution) setelah membuat keputusan, barulah seorang pemain melaksanakan macam-macam keterampilan yang dipilihnya.
5) Memberi dukungan (support) dengan gerakan tanpa bola pada posisi untuk menerima umpan atau melempar. 6) Melapis teman (cover) gerakan ini dilakukan untuk melapis pertahanan di belakang teman satu tim yang sedang berusaha menghalangi laju serangan lawan atau yang sedang bergerak ke arah lawan yang menguasai bola. 7) Menjaga atau mengikuti gerak lawan (guard or mark). Maksudnya adalah menahan laju gerakan lawan.

Dari ke tujuh penilaian yang diambil peneliti fokus hanya pada empat komponen yang dijadikan penilaian penelitian ini, dantaranya; melaksanakan keterampilan (skill execution), pengambilan keputusan (decision making), memberi dukungan (support) dan Menjaga atau mengikuti gerak lawan (guard or mark).

Analisa data penelitian yang dilakukan untuk menyelesaikan topik penelitian permasalahan ini ialah pertama mengitung nilai rata-rata dari kelompok sampel yang telah di standarisasikan, Kedua mengetahui simpangan baku atau standar deviation, ketiga melakukan uji normalitas data, kemudian keempat melakukan uji homogenitas, setelah itu kelima uji hipotesis. Setelah diketahui data berdistribusi normal dan homogen, maka dilakukan uji statistik parametrik dengan menggunakan two way anova dan tukey test. 


\section{HASIL DAN PEMBAHASAN}

Tabel 2. Deskripsi data penelitian

\begin{tabular}{|c|c|c|c|c|}
\hline \multirow[b]{2}{*}{$\begin{array}{c}\text { Tingkat } \\
\text { Intelligence } \\
\text { Quotient (IQ) }\end{array}$} & \multirow[b]{2}{*}{$\begin{array}{c}\text { Simbol } \\
\text { Statistik }\end{array}$} & \multicolumn{2}{|c|}{ Pendekatan Permainan } & \multirow[b]{2}{*}{ Total } \\
\hline & & $\begin{array}{c}\text { Tactical Games } \\
\text { Approach } \\
\text { (A1) }\end{array}$ & $\begin{array}{l}\text { Game Sense } \\
\text { Approach } \\
\text { (A2) }\end{array}$ & \\
\hline \multirow{5}{*}{ Tinggi (B1) } & $\mathrm{N}$ & 6 & 6 & 12 \\
\hline & $\sum \mathrm{x}$ & 42 & 6 & 48 \\
\hline & $\sum x^{2}$ & 340 & 1 & 341 \\
\hline & rata-rata & 7,00 & 1,00 & 8,00 \\
\hline & SD & 3,03 & 1,55 & 4,58 \\
\hline \multirow{5}{*}{ Rendah (B2) } & $\mathrm{N}$ & 6 & 6 & 12 \\
\hline & $\sum \mathrm{x}$ & 6 & 31 & 37 \\
\hline & $\sum \mathrm{x}^{2}$ & 22 & 207 & 229 \\
\hline & rata-rata & 1,00 & 5,17 & 6,17 \\
\hline & SD & 1,78 & 3,06 & 4,84 \\
\hline \multirow{5}{*}{ Total } & $\mathrm{N}$ & 12 & 12 & 24 \\
\hline & $\sum \mathrm{x}$ & 48 & 37 & 85 \\
\hline & $\sum \mathrm{x}^{2}$ & 362 & 225 & 587 \\
\hline & rata-rata & 8,00 & 6,17 & 14,17 \\
\hline & SD & 4,82 & 4,61 & 9,43 \\
\hline
\end{tabular}

Berdasarkan tabel 2 diatas diketahui rata-rata (mean) dari data gain skor antara pretest dan posttest masing-masing kelompok. Pada kelompok tingkat intelligence quotient (IQ) tinggi Tactical Games Approach (dan Game Sense Approach sebesar 7,00 dan 1,00. Pada kelompok tingkat Intelligence Quotient (IQ) rendah diperoleh rata-rata (mean) dari data gain skor antara pretest dan posttest kelompok Tactical Games Approach sebesar 1,00 dan Game Sense Approach sebesar 5,17. Selanjutnya, diketahui untuk keseluruhan jumlah rata-rata Tactical Games Approach dan Game Sense Approach pada kelompok tingkat Intelligence Quotient (IQ) tinggi dan rendah didapat sebesar 8,00 dan 6,17.

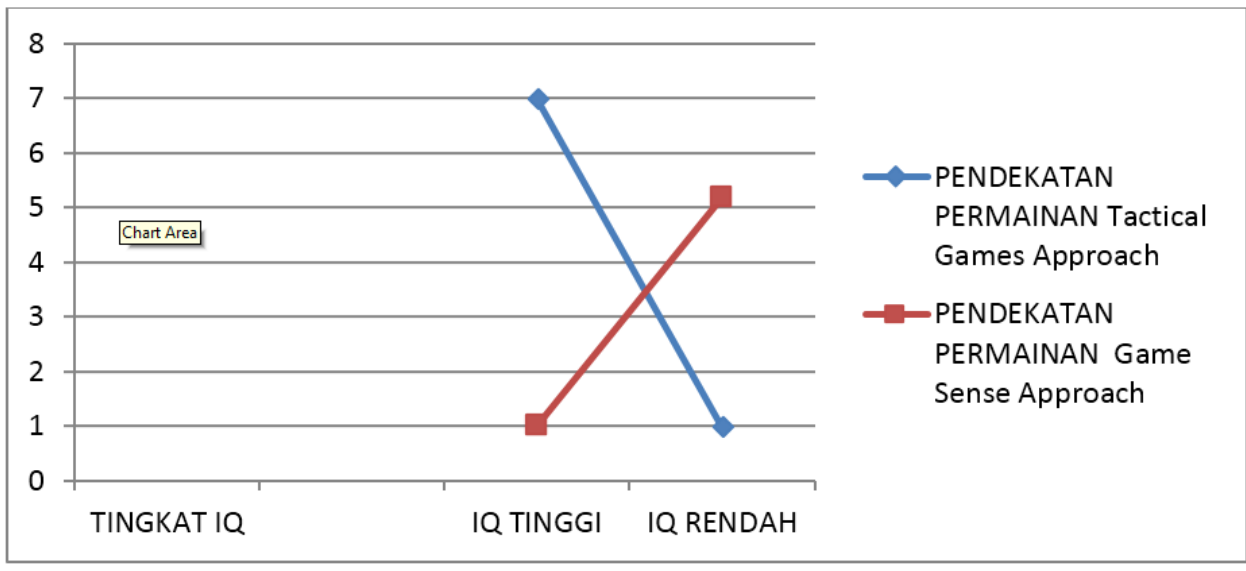

Gambar 1. Tingkat intelligence quotient (iq)

Berdasarkan gambar 1 Diagram diatas masing-masing kelompok tingkat intelligence quotient (IQ) dalam kedua pendekatan samasama mengalami peningkatan, namun jika dianalisa lebih mendalam peningkatan yang tejadi pada tingkat intelligence quotient (IQ) tinggi kelompok Tactical Games Approach lebih tinggi dibandingkan kelompok Game Sense Approach sedangkan pada tingkat intelligence quotient (IQ) rendah 
kelompok Game Sense Approach lebih tinggi dibandingkan kelompok Tactical Games Approach. Artinya, diagram diatas menunjukkan bahwa terdapat interaksi antara pendekatan permainan dan tingkat intelligence quotient (IQ) terhadap keterampilan bermain bolabasket.

Tabel 3. Hasil uji hipotesis 1

\begin{tabular}{ccc}
\hline F & Sig. & Keputusan \\
\hline 9,110 & 0,001 & Perbedaan Pengaruh \\
\hline
\end{tabular}

Berdasarkan Tabel 3 diperoleh nilai sig $=0,01>0,05$ maka Ho ditolak atau terdapat perbedaan pengaruh antara pendekatan permainan (tactical games aproach dan game sense approach)dan tingkat intelligence quotient (IQ) terhadap keterampilan bermain bola basket. Kesempurnaan taktik suatu tim atau individu merupakan salah satu faktor determinan yang sukses dalam olahraga terutama dalam team sports atau olahraga beregu (Harsono, 2017:46). Hal tersebut menjelaskan bahwa pemahaman mengenai masalah taktis sangat penting untuk olahraga beregu seperti bola basket. Seseorang yang terampil dan memiliki banyak pengetahuan tentang bola basket menunjukkan kinerja yang lebih baik dalam situasi permainan yang sebenarnya. Seseorang harus terlebih dahulu mengembangkan basis pengetahuan dalam olahraga yang diberikan sebelum dapat mencukupi dan mengembangkan keterampilan pengambilan keputusan yang baik.

Aspek psikologis yang merupakan level intelligence quotient (IQ) merupakan elemen yang memiliki peran penting untuk keterampilan basket, terutama dalam menguasai dan menganalisis berbagai keterampilan gerakan dalam bola basket (Kusuma \& Kristiyanto, 2017).

Tabel 4. Hasil uji hipotesis 2

\begin{tabular}{ccc}
\hline F & Sig. & Keputusan \\
\hline 25,662 & 0,000 & Terdapat Interaksi \\
\hline
\end{tabular}

Selanjutnya, pada tabel 4 diperoleh nilai $\mathrm{F}=25,662$ dan $\operatorname{sig}=0,000<0,05$ maka Ho ditolak, atau Terdapat interaksi antara pendekatan permainan dan tingkat intelligence quotient (IQ) terhadap keterampilan bermain bola basket. Hasil tersebut menunjukkan bahwa atlet yang mempunyai tingkat intelligence quotient (IQ) tinggi dan diterapkan tactical games approach pada proses latihan memberikan pengaruh terhadap keterampilan bermain bola basket dibandingkan dengan atlet yang memiliki tingkat intelligence quotient (IQ) rendah yang samasama diterapkan tactical games approach.

Tabel 5. Hasil uji hipotesis 3

\begin{tabular}{cc}
\hline Sig. & Keputusan \\
\hline 0,002 & Perbedaan Pengaruh \\
\hline
\end{tabular}

Pada tabel 5 diatas diperoleh nilai sig $=0,002<0,05$ maka Ho ditolak, atau terdapat perbedaan pengaruh antara pendekatan permainan pada kelompok intelligence quotient (IQ) tinggi terhadap keterampilan bermain bola basket. Dapat dikatakan bahwa pemain yang memiliki kemampuan taktis dapat menemukan pengaturan dalam permainan, hal ini berhubungan dengan kecerdasan pemain tersebut. Kecerdasan sering dikaitkan dengan kemampuan intelegensi seseorang. Semakin tinggi tingkat Intelegensi seseorang akan semakin tinggi prestasi yang akan dicapai, bahkan menurut sebagian besar intelegensi merupakan modal utama dalam mempelajari dan mencapai hasil optimal.

Tabel 6. Hasil uji hipotesis 4

\begin{tabular}{cc}
\hline Sig. & Keputusan \\
\hline 0,038 & Perbedaan Pengaruh \\
\hline
\end{tabular}

Terlihat pada tabel 6 diatas diperoleh nilai sig $=0,008<0,05$ maka Ho ditolak, atau terdapat perbedaan pengaruh antara pendekatan permainan pada tingkat intelligence quotient (IQ) rendah terhadap keterampilan bermain bola basket.

\section{KESIMPULAN}

Berdasarkan hasil pengolahan analisis data penelitian yang telah dilakukan untuk menjawab pertanyaan penelitian yang sudah diajukan, diperoleh jawaban bahwa terdapat perbedaan pendekatan permainan dan tingkat intelligence quotient (IQ) terhadap keterampilan bermain bola basket, 
secara keseluruhan pendekatan tactical games apporach lebih unggul dibandingkan pendekatan game sense approach terhadap keterampilan bermain bola basket. Diidentikkan dengan pendekatan taktik atau tactical approach, pendekatan permainan taktis (TGA) utamanya berfokus pada peningkatan kinerja permainan. Tactical games approach dapat memprioritaskan aspek pengambilan keputusan dari game dan mendorong siswa dan pemain untuk menggunakan keterampilan pemecahan masalah mereka (Dyson et al., 2004). Pendapat lain dikemukakan oleh Mitchell, Oslin, \& Griffin (2013) mengatakan bahwa taktik dan keterampilan berkembang dalam urutan bentuk-bentuk permainan yang masingmasing berisi masalah taktis dinyatakan untuk menentukan tujuan pembelajaran tugas saat ini. Selain itu keduanya memiliki interaksi terhadap keterampilan bermain bola basket pada atlet UKM bola basket putri UPI Bandung. Selanjutnya hasil penelitian menunjukkan bahwa pendekatan tactical games approach lebih baik diterapkan pada kelompok tingkat intelligence quotient (IQ) tinggi dan game sense approach lebih baik diterapkan pada kelompok tingkat intelligence quotient (IQ) rendah.

\section{DAFTAR PUSTAKA}

Bazanov, B., \& Haljand, R. (2017). Factors Influencing The Teamwork Intensity In Basketball. 8668 (November). Https://Doi.Org/10.1080/24748668.2006.11868375.

Breed, R., \& Spittle, M. (2011). Developing Game Sense Through Tactical Learning : A Resource For Teachers And Coaches. Port Melbourne: Cambridge University Press.

Csataljay, G., Donoghue, P. O., Hughes, M., \& Dancs, H. (2017). Performance Indicators That Distinguish Winning And Losing Teams In Basketball. 8668( June).

Dyson, B., Griffin, L. L., \& Hastie, P. (2004). Sport Education, Tactical Games, And Cooperative Learning : Theoretical And Pedagogical Considerations. (July 2013), 37-41. Https://Doi.Org/10.1080/00336297 .2004.10491823.

French, K. E., \& Thomas, J. R. (1987). The Relation Of Knowledge Development To Children 'S Basketball Performance. 15-32.

Georgakis, S., \& Light, R. (2007). The Effect Of Game Sense Pedagogy On Primary School Pre-Service Teachers' Attitudes To Teaching Physical Education. ACHPER Australia Healthy Lifestyles Journal , 54(1), 24 28.

Gómez-Haro, S., \& Salmerón-Gómez, R. (N.D.). Coaching : An International Journal Of Theory, Research And Practice Life Cycles Or Longer Tenures? A Performance And Employment Duration Model For Spanish Basketball Coaches. (May 2015), 37-41. Https://Doi.Org/10.1080/17521882.2014.993672.

Gubacs-Collins, K., Olsen, E. B., \& Gubacs-Collins, K. (2013). Journal Of Physical Education, Recreation \& Dance. (March 2015), 37-41. Https://Doi.Org/10.1080/07303084.2010.10598447.

Haneishi, K. (2014). Impacts Of The Game-Centered Approach On Cognitive Learning Of Game Play And Game Performance During 5-Week Of Spring Season With Intercollegiate Female Soccer Players.

Harsono. (2017). Kepelatihan Olahraga Teori Dan Metodologi. Bandung: PT Remaja Rosdakarya.

Hawkins, J. R., Sharp, E. B., \& Williams, S. M. (2015). Take A Page From Your Coach 'S Play Book: Teaching Technical And Tactical Skills In Athletic Training Take A Page From Your Coach 'S Play Book : Teaching Technical And Tactical Skills In Athletic Training. 10(3), 244-248. Https://Doi.Org/10.4085/1003224.

Issue, M. (2003). This Material May Not Be Reproduced, Stored In A Retrieval System Or Transmitted By Any Means, Electronic, Mechanical, Photocopying Without The Permission Of The Copyright Holder Author Tim Hopper. Journal Of Teaching Elementary Physical Education, March. 1-12.

Khodijah, N. (2016). Psikologi Pendidikan (Ketiga). Jakarta: PT Raja Grafindo Persada.

Kirk, D., \& Macphail, A. (2002). Teaching Games For Understanding And Situated Learn- Ing : Rethinking The Bunker-Thorpe Model. 177-192.

Kusuma, H., \& Kristiyanto, A. (2017). European Journal Of Physical Education And Sport Science The Relationship Of Intelligence Quotient (IQ), Emotional Quotient (EQ), And Motivation Towards. (4), 1-12. Https:// Doi.Org/10.5281/Zenodo.439993.

Launder, A., \& Piltz, W. L. (2006). Beyond Understanding To Skilful Play In Games, Through Play Practice. 
Journal Of Physical Education New Zealand, 39(1), 47-57.

Light, R. (2013). Game Sense: Pedagogy For Performance, Participation And Enjoyment. Abingdon, Oxon: Routledge.

Mawarti, S. (N.D.). Tactical Games Approach Dalam Pembelajaran Bolavoli Siswa Sekolah Dasar. 3(1), 13-22.

Mcmorris, T., \& Mcmorris, T. (2006). Teaching Games For Understanding : Its Contribution To The Knowledge Of Skill Acquisition From A Motor Learning Perspective Teaching Games For Understanding : Its Contribution To The Knowledge Of Skill Acquisition From A Motor Learning Perspective. (July 2013), 37-41. Https://Doi.Org/10.1080/1740898980030106.

Metzler, M. W. (2005). Instructional Models For Physical Education. Scottsdale, AZ: Holcomb Hathaway Publishers.

Mitchell, S. A., Oslin, J. L., \& Griffin, L. L. (2013). Teaching Sport Concepts And Skills : A Tactical Games Approach For Ages 7 To 18. USA: Human Kinetics.

Piette, J., Pham, L., \& Anand, S. (2011). Evaluating Basketball Player Performance Via Statistical Network Modeling. 1-11.

Pill, S. (2013). Journal Of Physical Education, Recreation \& Dance. (October 2014), 37-41. Https://Doi.Org/10. 1080/07303084.2012.10598746.

Series, I. O. P. C., \& Science, M. (2017). Contribution Of Intelligence And Emotional Qoutients With Performance Athletes Pencak Silat Contribution Of Intelligence And Emotional Qoutients With Performance Athletes Pencak Silat. Https://Doi.Org/10.1088/1742-6596/755/1/011001.

Setiadi. (2001). Teaching Games For Understanding. 1-13.

Thembelihle, G., \& Timothy, G. K. (2018). European Journal Of Physical Education And Sport Science Adopting Game Sense Approach To Teaching And Coaching Of. 129-140. https://doi.org/10.5281/ zenodo. 1214697. 